\title{
Carrier PrimeLine extended defrost software scr19521.ml3 testing
}

Dr. Leo Lukasse

Marcel Staal

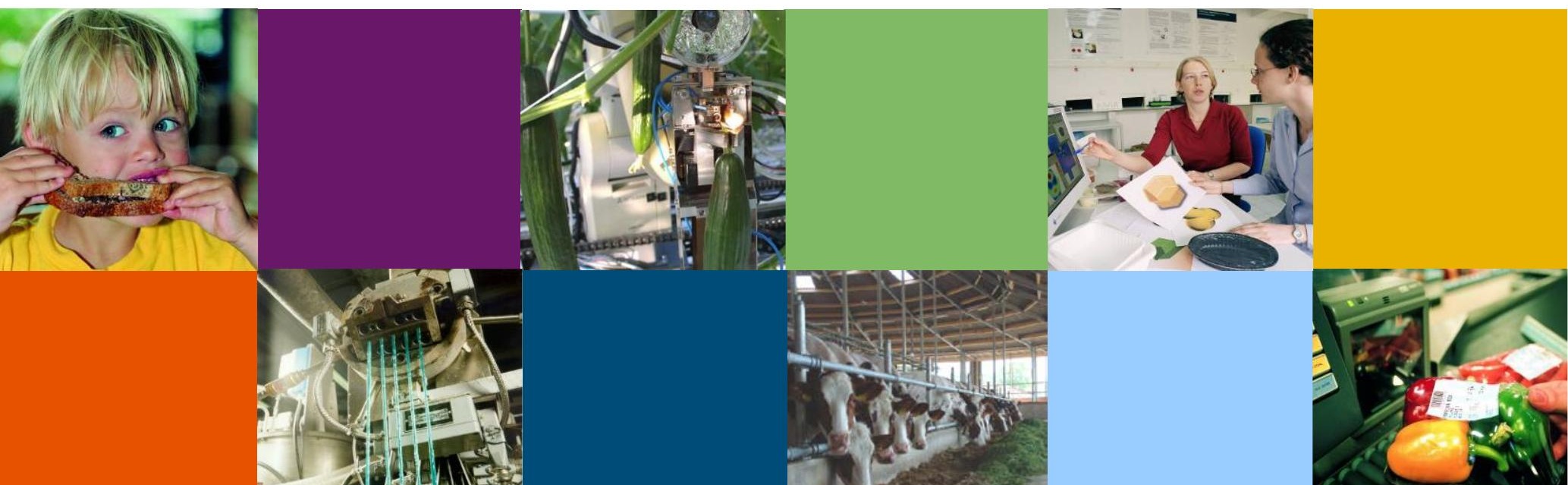




\section{Colophon}

Title

Author(s)

Number

ISBN-number

Date of publication

Version

Confidentiality

project number

Approved by

Review

Name reviewer

Sponsor

Client
Carrier PrimeLine extended defrost software scrl9521.ml3 testing

Dr. Leo Lukasse, Marcel Staal

1677

$\mathrm{N} / \mathrm{A}$

Sept. 2016

1.0

yes, till three years after date of publication

6239117000

Ir. Janneke de Kramer

Internally peer-reviewed

Gerard Leentfaar

Maersk Line

Maersk Line

Wageningen UR Food \& Biobased Research

P.O. Box 17

NL-6700 AA Wageningen

Tel: +31 (0)317480084

E-mail: info.fbr@wur.nl

Internet: www.wageningenur.nl/en/fbr

(C) Wageningen UR Food \& Biobased Research, institute within the legal entity Stichting Dienst Landbouwkundig Onderzoek

All rights reserved. No part of this publication may be reproduced, stored in a retrieval system of any nature, or transmitted, in any form or by any means, electronic, mechanical, photocopying, recording or otherwise, without the prior permission of the publisher. The publisher does not accept any liability for inaccuracies in this report.

This report can be downloaded for free from September 2019 at https://doi.org/10.18174/563046/ or at www.wur.nl/wfbr (under publications). 


\section{Abstract}

In some frozen mode shipments the moisture load can be so high that frost accumulates in the reefer unit. This happens on components above the evaporator coil, the highest component being the return air grid. In reaction to a specification provided by Maersk Line, Carrier has delivered a software solution to that problem (scrl9521.ml3). The aim of this test is to experimentally assess the efficacy of Carrier's software solution to the ice/frost formation problem in frozen mode shipments with a high moisture load.

To that end, a reefer container with Carrier PrimeLine refrigeration unit was placed in a climate chamber. In a series of tests the unit was set at $-20{ }^{\circ} \mathrm{C}$ and it was subjected to an extreme moisture load for multiple days.

The results show that Carrier's software scrl9521.ml3 is an effective solution to the ice/frost formation problem in frozen mode shipments with high moisture load. However, two concerns remain:

1. It is inherent to the implemented software logic that there is no guarantee of a frost-free return air grid at defrost termination.

2. The alarms generated during the test deserve attention. 


\section{Content}

Abstract 3

1 Introduction $\quad 5$

2 Test equipment 6

2.1 Software specification 8

3 Materials and methods 9

4 Results 12

5 Discussion $\quad 19$

6 Conclusion $\quad 20$

$\begin{array}{lr}\text { References } & 20\end{array}$

$\begin{array}{lr}\text { Acknowledgements } & 20\end{array}$ 


\section{Introduction}

In some frozen mode shipments the moisture load may be such high that frost accumulates in the reefer unit on components above the evaporator coil, the highest component being the return air grid.

Maersk Line has provided Carrier with specification for a software solution. In reaction to that Carrier has delivered a software solution (scr19521.ml3), but deviant from the Maersk Line specs. The aim of this test is to experimentally assess the efficacy of Carrier's software solution to the ice/ frost formation problem. 


\section{Test equipment}

All tests are performed in our test chamber for refrigerated transport equipment (Fig. 1). Power supply during all tests: $50 \mathrm{~Hz} / 400 \mathrm{~V}$.
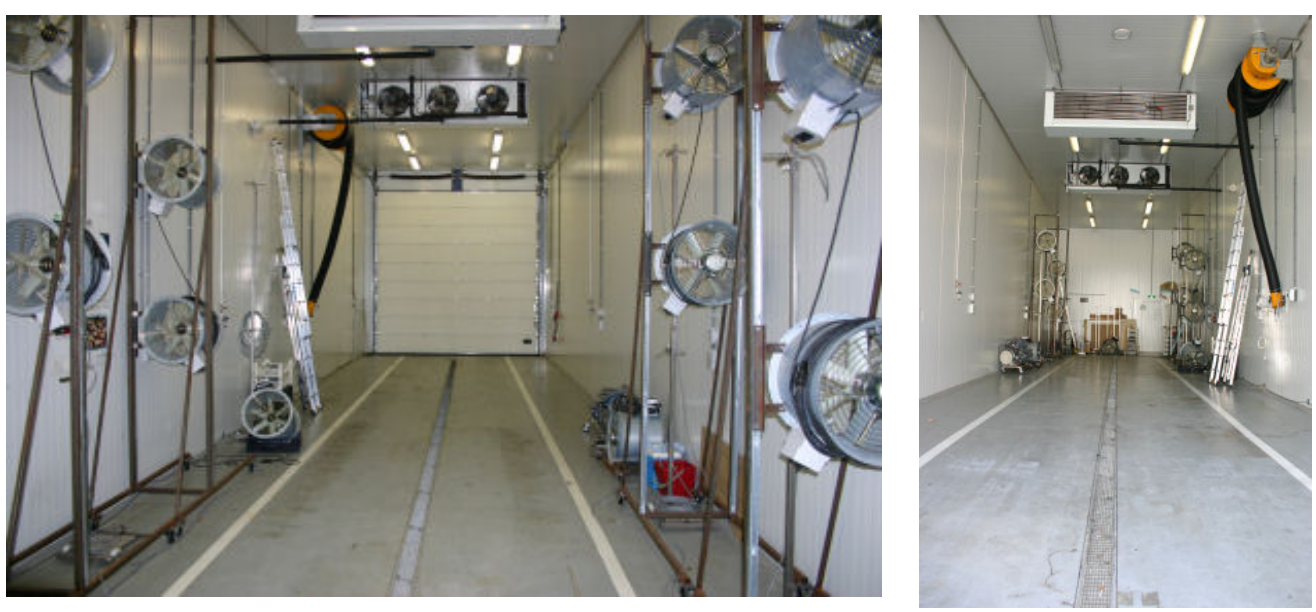

Fig. 1, climate chamber used.

A series of tests has been performed on container MNBU017582[5] (Fig. 2).

See Fig. 2, Fig. 3, Table 1 and Table 2 for further specs of the test equipment.
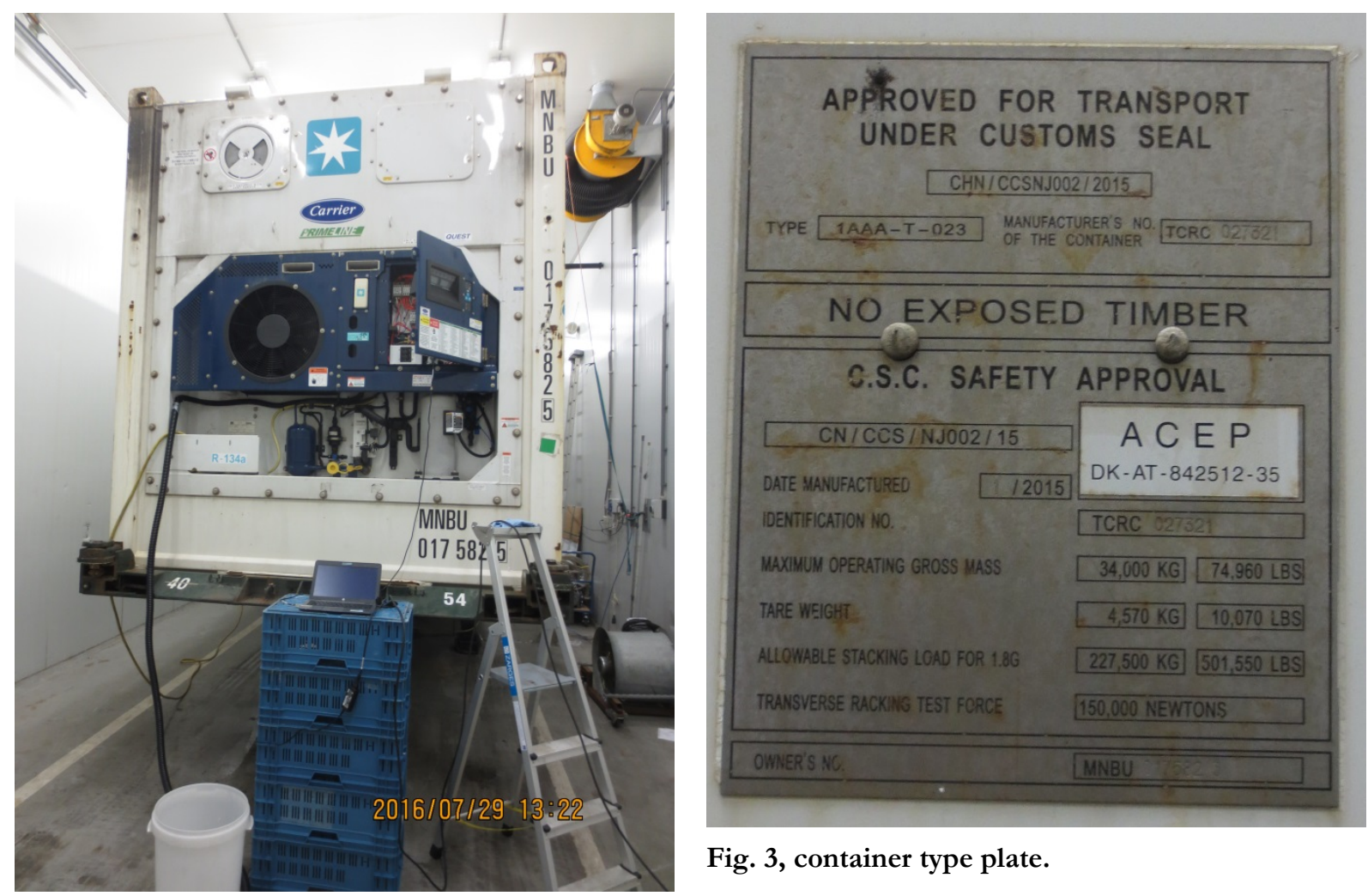

Fig. 3, container type plate.

Fig. 2, test container in climate chamber. 
Table 1, characteristics of equipment used in tests.

\begin{tabular}{|l|l|l|l|l|l|}
\hline & manufacturer & $\begin{array}{l}\text { man. } \\
\text { date }\end{array}$ & model no. & $\begin{array}{l}\text { identification } \\
\text { no. }\end{array}$ & last PTI \\
\hline container & N/A & N/A & N/A & MNBU017582[5] & N/A \\
\hline unit & Carrier & unknown & $\begin{array}{l}69 \text { NT40-561- } \\
216\end{array}$ & unknown & unknown \\
\hline box & unknown & Jan. 2015 & 1AAA-T-0023 & TCRC027321 & N/A \\
\hline
\end{tabular}

Table 2, reefer unit specs.

\begin{tabular}{|l|l|}
\hline characteristic & value \\
\hline software version & scrl9521.ml3 \\
\hline defrost interval & AUTO \\
\hline $\begin{array}{l}\text { defrost water } \\
\text { drain-off system } \\
\text { (see also Fig. 5): }\end{array}$ & $\begin{array}{l}\text { - } \\
\text { eacho rubber drain pans sunken into unit's front panel. }\end{array}$ \\
& $\begin{array}{l}\text { unit's front panel, guiding melt water to the pans. } \\
\text { evap. coil tilted towards unit's front panel }\end{array}$ \\
\hline
\end{tabular}

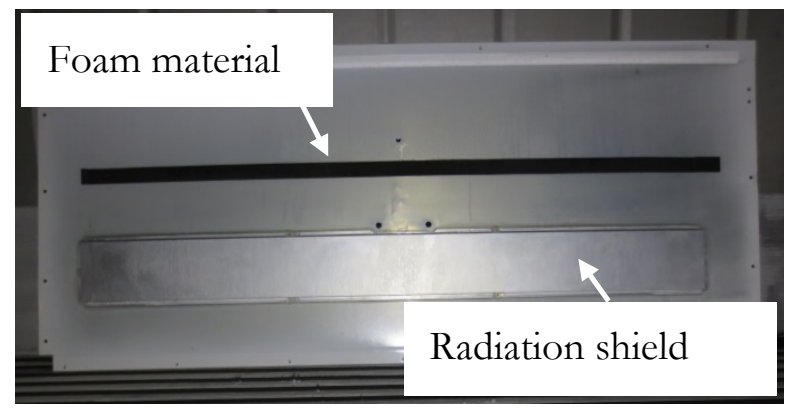

Fig. 4, unit's upper rear panel with no drain gutter or pan, flexible foam insulation strip closing the gap between evap. coil and panel (1), radiation shield (2).

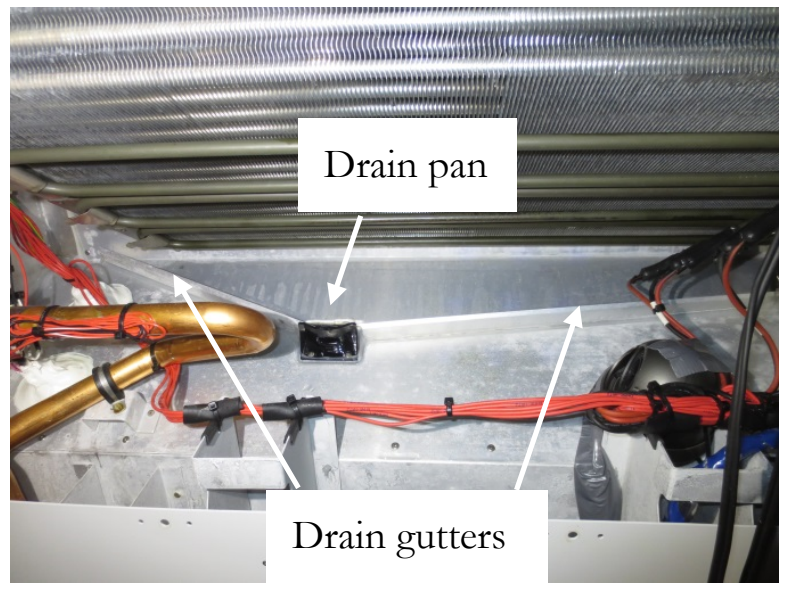

Fig. 5, drain gutters and pan on unit's front wall. 


\subsection{Software specification}

Software version scrl9521. $\mathrm{ml} 3$ is used in the test. The defrost logic specs are:

If $\operatorname{cd} 27$ (defrost interval) $=$ AUTO (only) then defrosts are extended defrosts. Extended defrosts only differ from normal defrosts in their termination logic. The extended defrosts termination logic is:

1. Defrost enters extension stage when DTS $>32{ }^{\circ} \mathrm{C}$. During this defrost extension stage Heaters, Fans, and Compressor are off, defrost LED is on.

2. Defrost extension stage terminates after 10 minutes.

3. After termination of extension stage the unit starts cooling again. 


\section{Materials and methods}

Two tests were run (Table 4).

Table 3 , test conditions equal during all tests.

\begin{tabular}{|l|l|}
\hline Parameter & Value \\
\hline $\mathrm{T}_{\text {set }}$ & $-20.0{ }^{\circ} \mathrm{C}$ \\
\hline $\mathrm{T}_{\text {chamber,set }}$ & $+20.0^{\circ} \mathrm{C}$ \\
\hline
\end{tabular}

Table 4, test specific conditions

\begin{tabular}{|l|l|l|}
\hline parameter & test $\mathbf{1}$ & test $\mathbf{2}$ \\
\hline $\mathrm{r}_{\text {hum }}$ & $2 \mathrm{~L} / \mathrm{h}$ & $0.25 \mathrm{~L} / \mathrm{h}$ \\
\hline start & 22 July 2016 11:00 & 26 July 2016 9:00 \\
\hline end & 25 July 10:48 & 28 July 13:00 \\
\hline duration & 3 days & 2 days \\
\hline
\end{tabular}

During the tests the container's interior is humidified with an ultrasonic humidifier (manufacturer Contronics, type HU-45). For more details see

http://www.contronics.nl/product/detail/21/31/Humidifier-HU-45. To avoid freezing of the humidifier the humidifier is place outside the container. The fog is blown into the container through a chink between the container doors. The remainder of the chink is closed as well as possible with EPS foam blocks (see Fig. 9).

Three temperature sensors are placed (see Table 5, Fig. 6, Fig. 7).

Table 5, temperature sensor placement

\begin{tabular}{|l|l|}
\hline $\begin{array}{l}\text { sensor } \\
\text { name }\end{array}$ & description \\
\hline ATP1 & ATP sensor placed $20 \mathrm{~cm}$ above the floor at approx. $4 \mathrm{~m}$. from the unit-end. \\
\hline ATP2 & ATP sensor placed in return air grid \\
\hline LogTag & $\begin{array}{l}\text { A LogTag trix-8 recorder placed against the unit's lower rear panel with an insulated } \\
\text { gasket over it to measure rear panel temperature and not the air temperature. }\end{array}$ \\
\hline
\end{tabular}




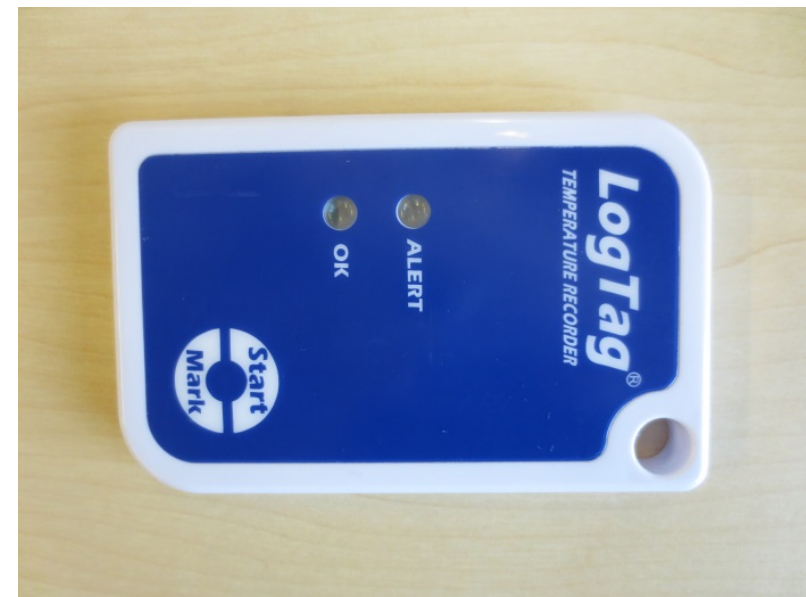

Fig. 6, LogTag logger.

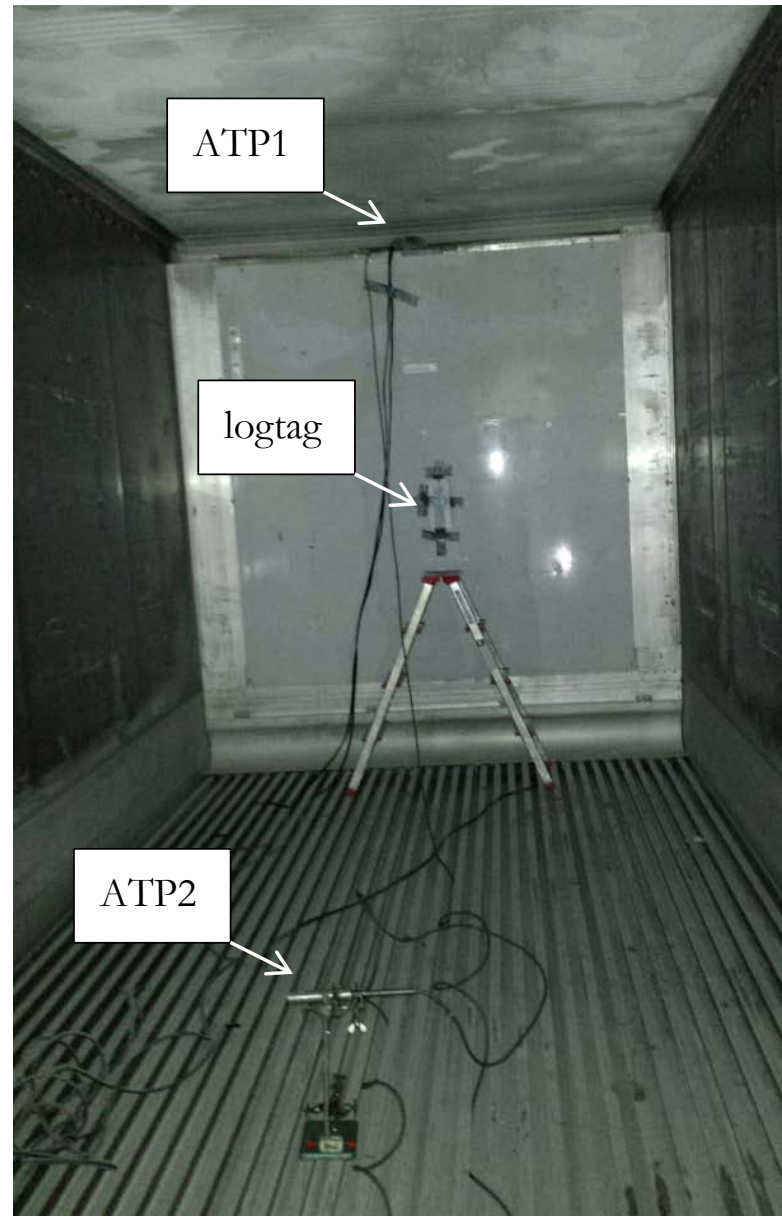

Fig. 7, placement of additional sensors.

Four infrared cams are mounted in the reefer unit. Fig. 8 depicts how these are mounted. The cameras record both videos and photos at 1 minute intervals. Fig. 10 shows the screen, placed in the test chamber, at which the four images are shown live. 


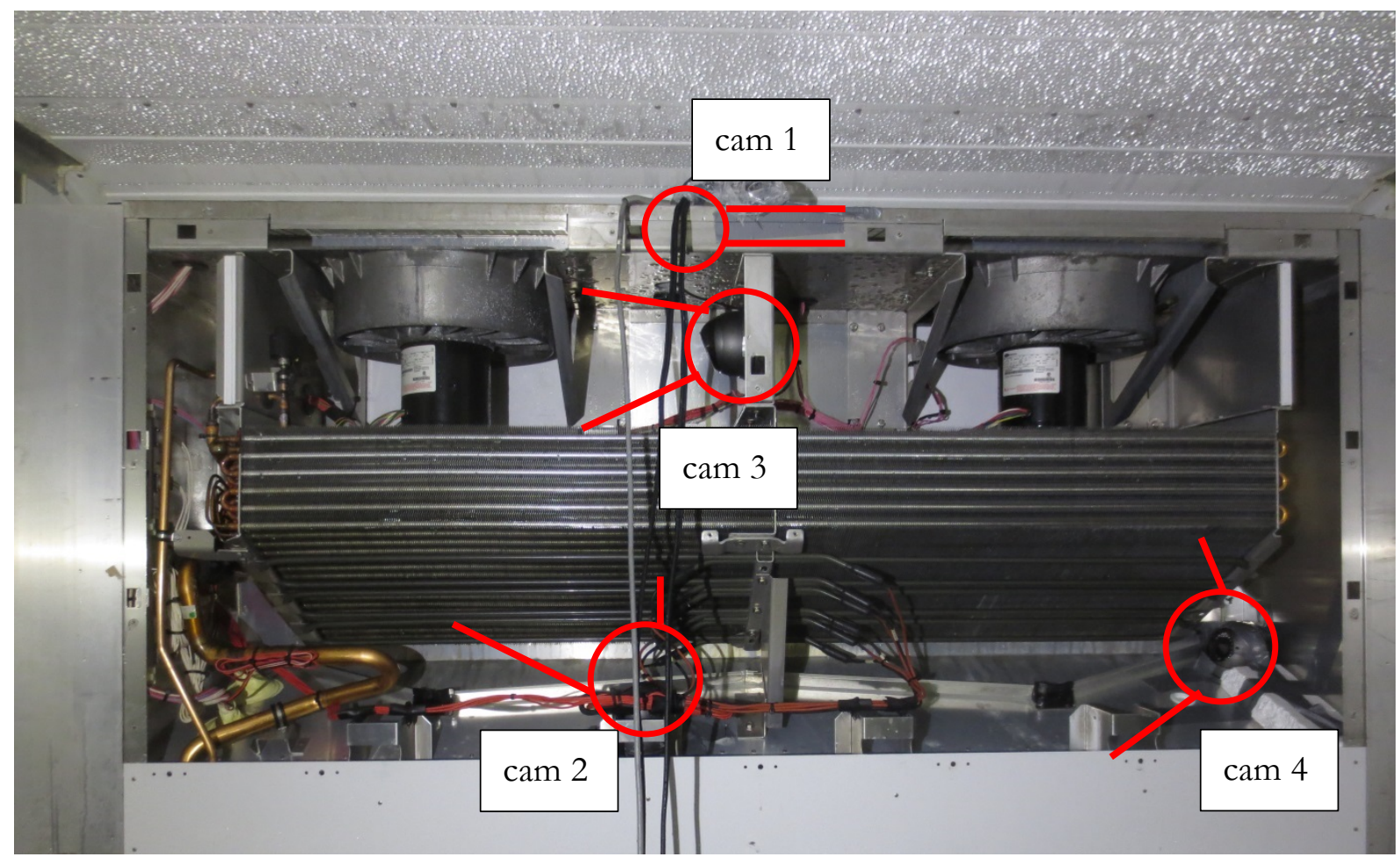

Fig. 8, four IR cameras and their field of view.
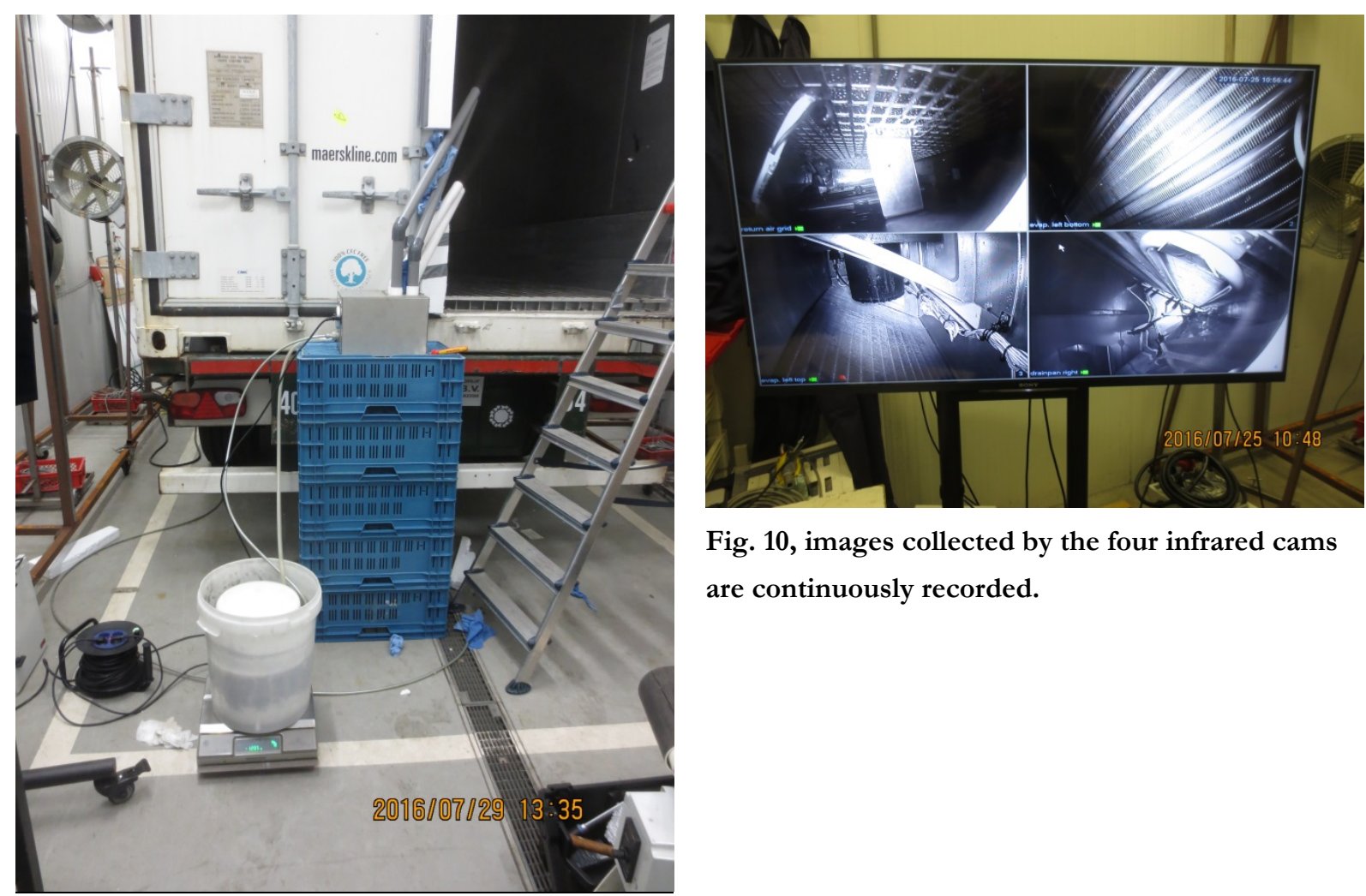

Fig. 10, images collected by the four infrared cams are continuously recorded.

Fig. 9, humidification through door chink. 


\section{Results}

In the unit download and on the unit's display, many alarms occur, also during defrost (see Fig. 11). According to Dataview the alarms are mostly alarm 72 (unsupported alarm), it occurs many times in the unit's datalog, also during defrosts. Two times the alarm 64 (discharge temp over limit) occurs, both times during defrost. It is worrying to see that the alarm numbers are different when viewing the datafile through LogView (compare Table 6 to Table 7).

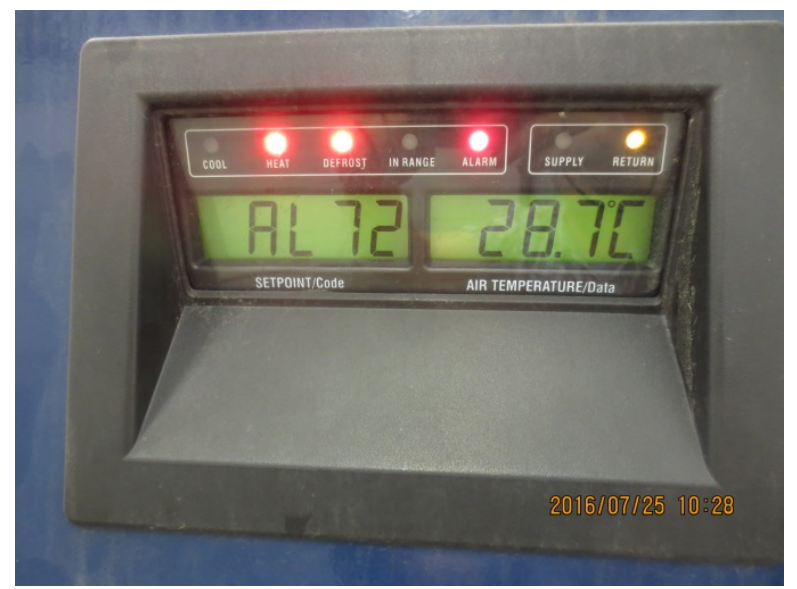

Fig. 11, many alarms occur during the test. It's mostly al72, 2x al64.

Table 6, controller alarm seen in MNBU0175825aa.dcx when opened with Carrier Dataline version 2.2.0. jul 22, 2016 Time Event Data

19:50 Defrost Initiated Due to Delta Temp

19:50 Operating Mode Changed to Defrost

20: $\odot \odot$ Controller Alarms: 72 - Unsupported Alarm

Table 7, controller alarm seen in MNBU0175825aa.dcx when opened with LogView

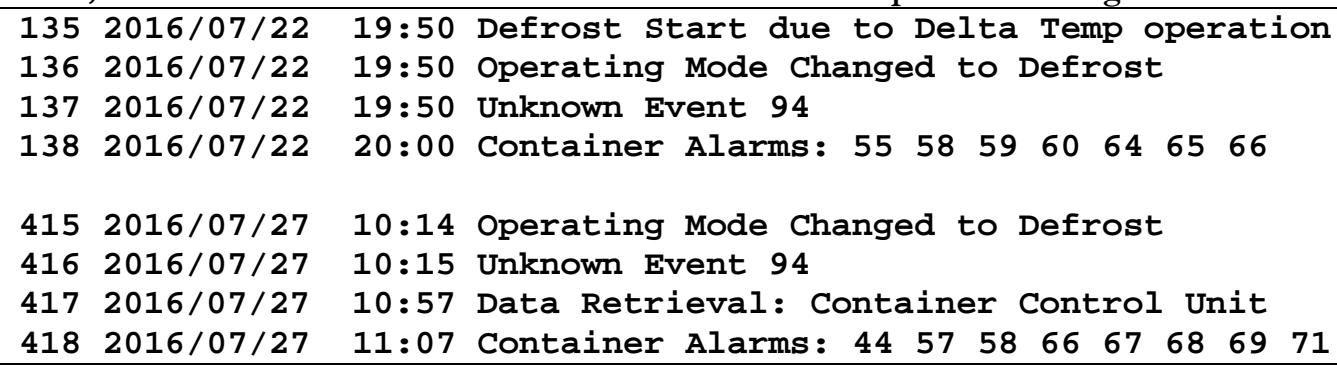

Fig. 12 and Fig. 14 present the unit's Tsup and Tret recorded during test 1 and 2. Note the perfectly repetitive pattern in Tsup and Tret. Fig. 13 presents all temperatures recorded during the last three defrost cycles of test 1. 


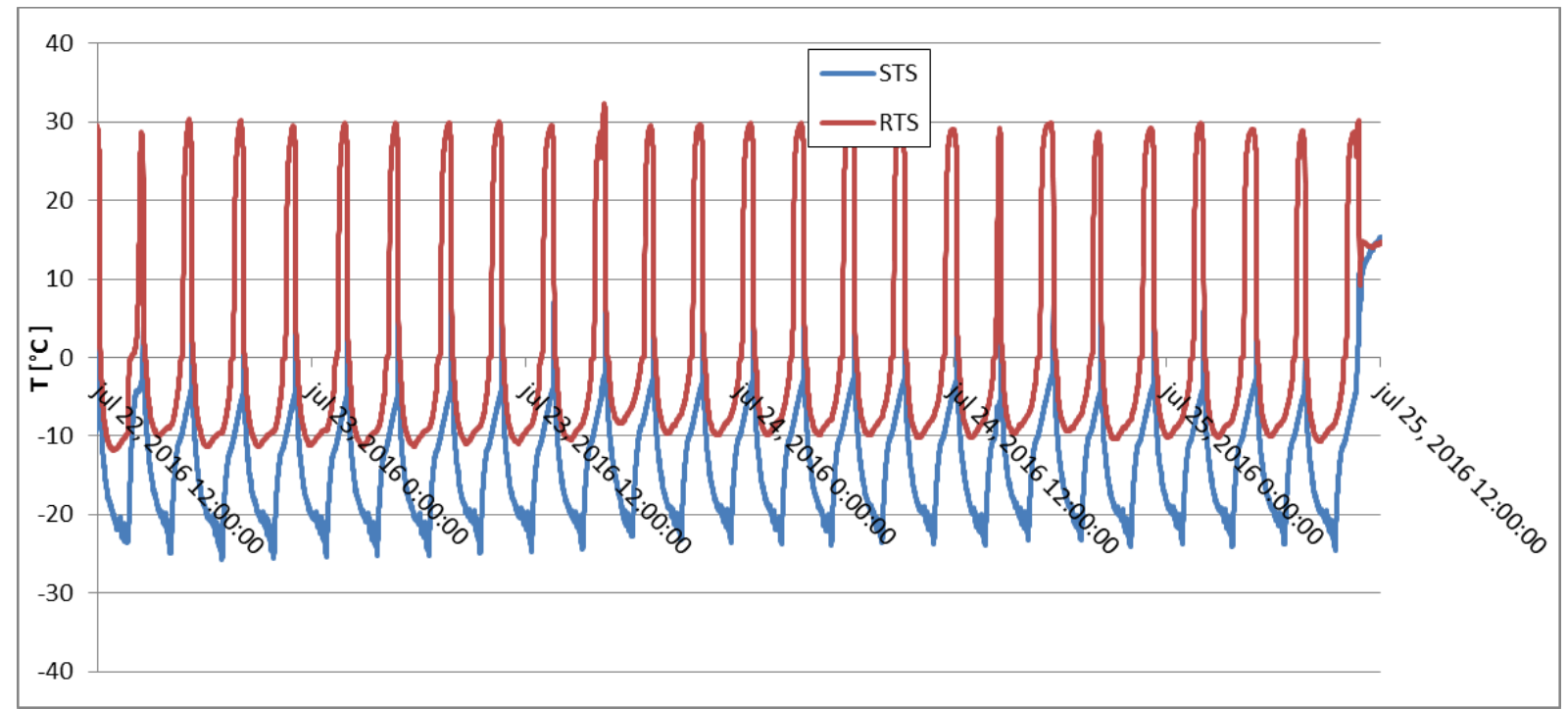

Fig. 12, Tsup and Tret recorded during test $1\left(\mathrm{r}_{\mathrm{hum}}=2 \mathrm{~L} / \mathrm{h}\right)$.

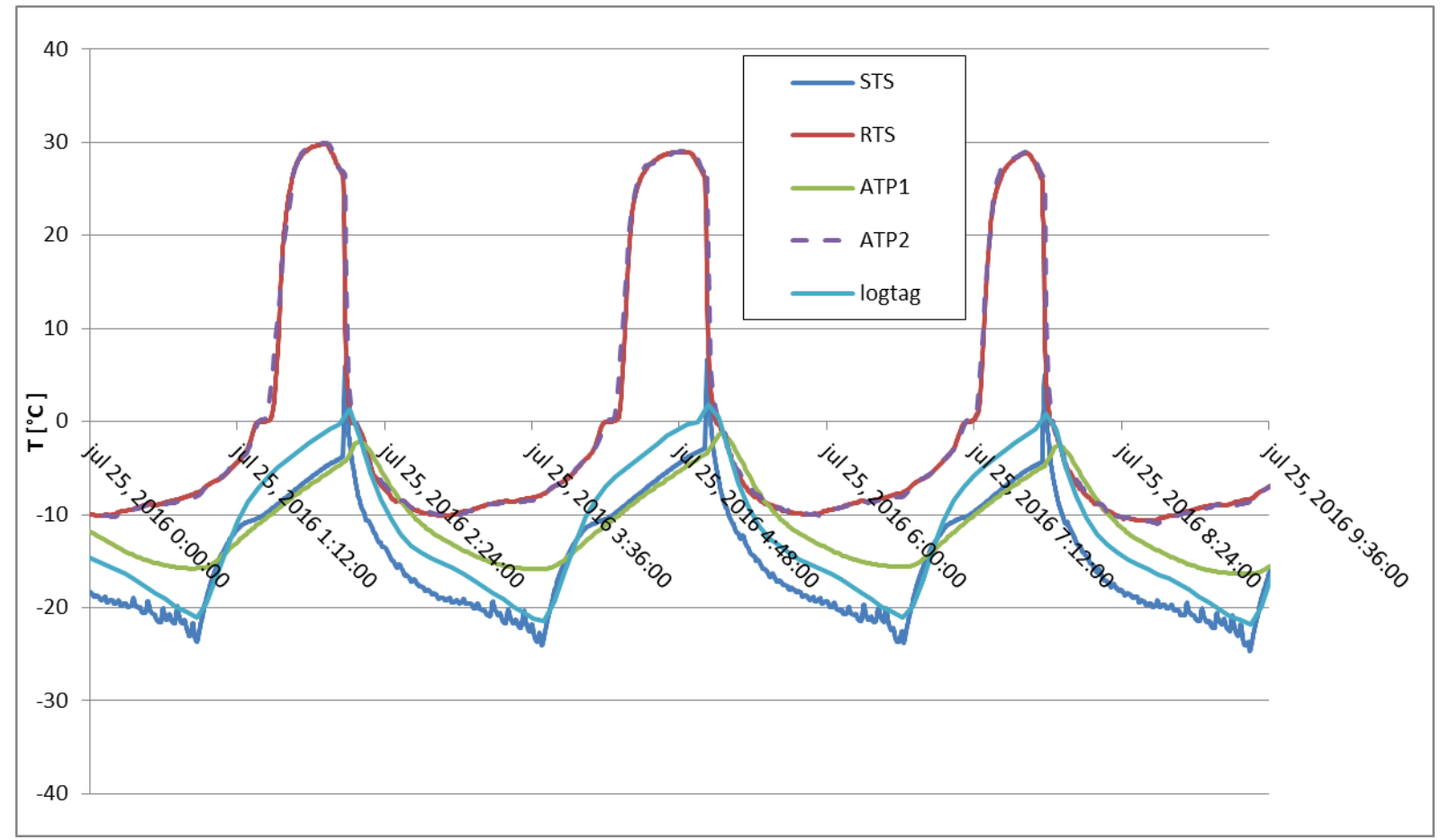

Fig. 13, all temperatures recorded during last 3 defrost cycles of test $1\left(\mathrm{r}_{\text {hum }}=2 \mathrm{~L} / \mathrm{h}\right)$. 


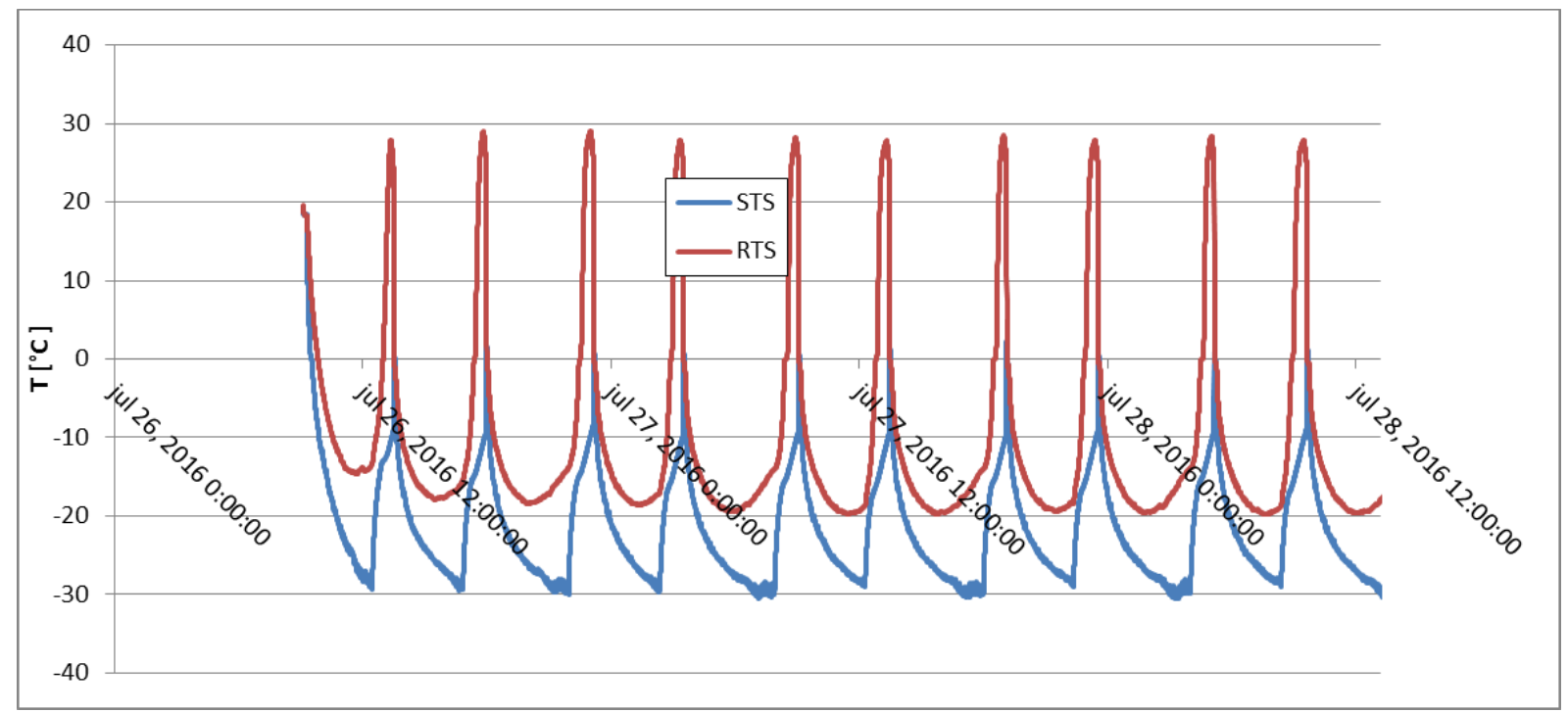

Fig. 14, Tsup and Tret recorded during test $2\left(\mathrm{r}_{\text {hum }}=0.25 \mathrm{~L} / \mathrm{h}\right)$.

Fig. 15 - Fig. 22 are the images taken by the four IR cameras at start and end of defrost starting 25-7-2016 3:40 and ending 25-7-2016 5:00 (datamonitor file time), one of the lasts defrost during test 1 .

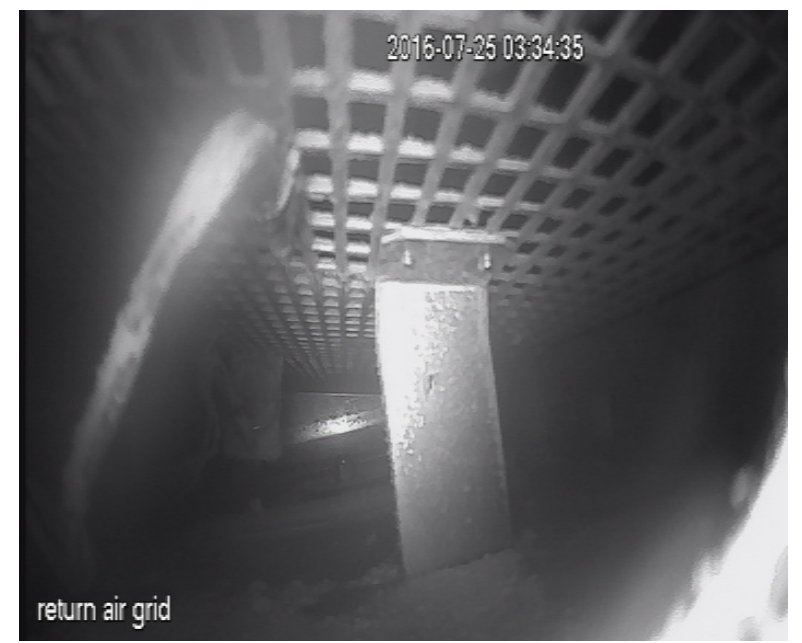

Fig. 15, cam 1 at start of defrost 7 (25-7-'16 3:40).

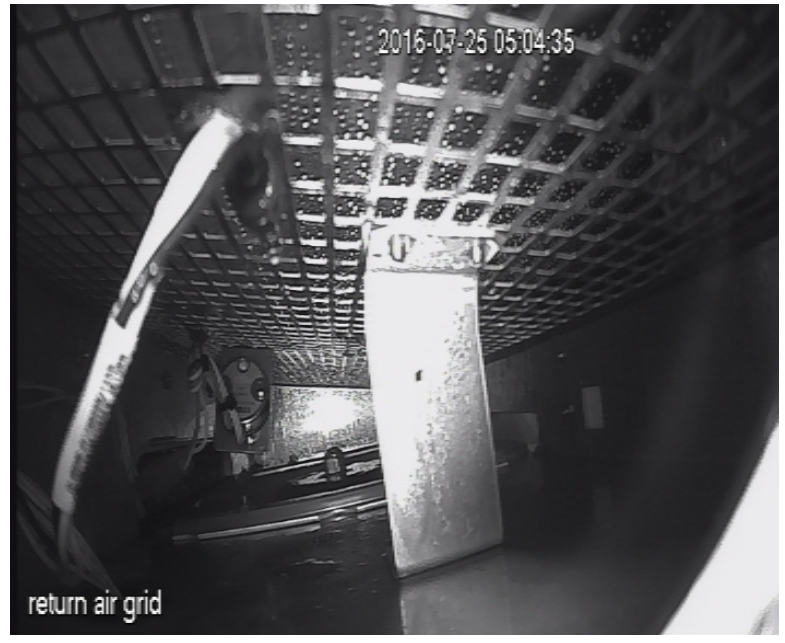

Fig. 16, cam 1 at end of defrost 7 (25-7-'16 5:00). 


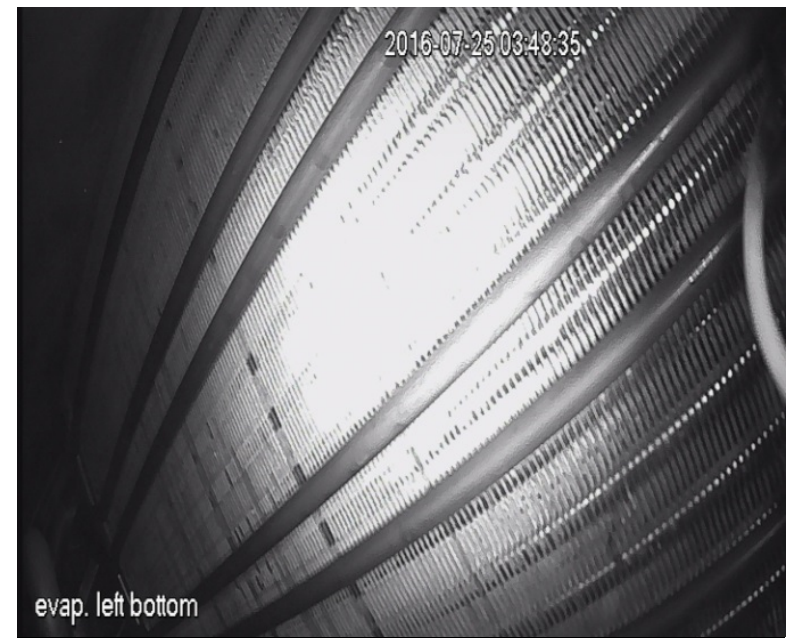

Fig. 17, cam 2 at start of defrost 7 (25-7-'16 3:40).

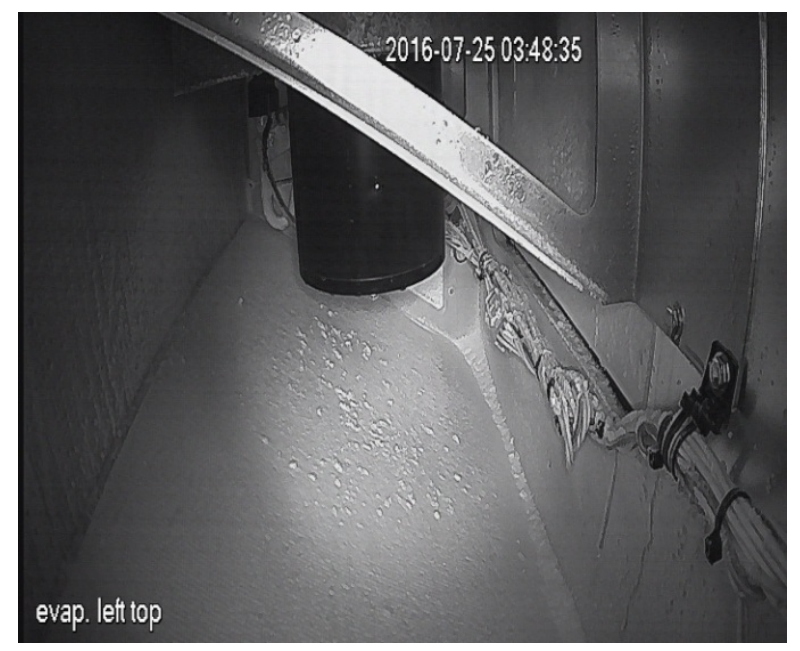

Fig. 19, cam 3 at start of defrost 7 (25-7-'16 3:40).

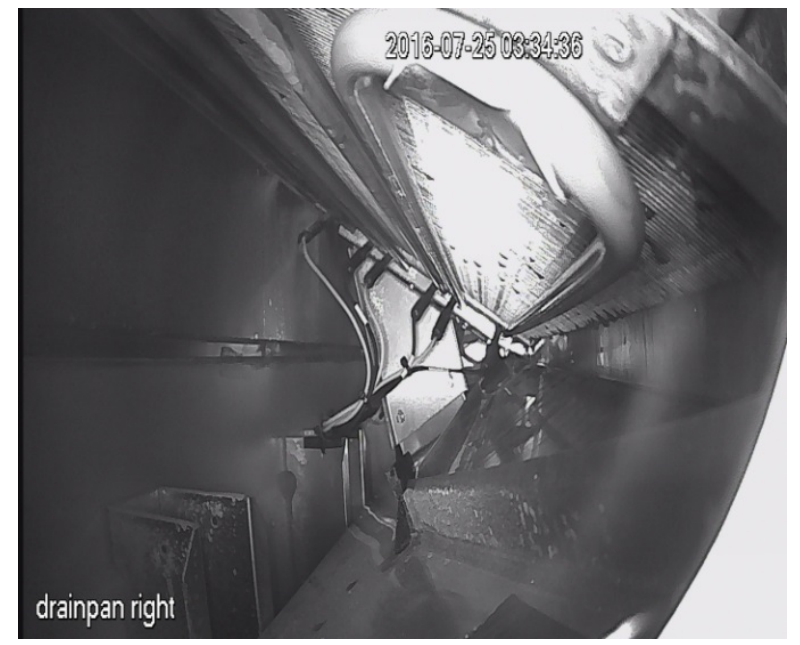

Fig. 21, cam 4 at start of defrost 7 (25-7-'16 3:40).

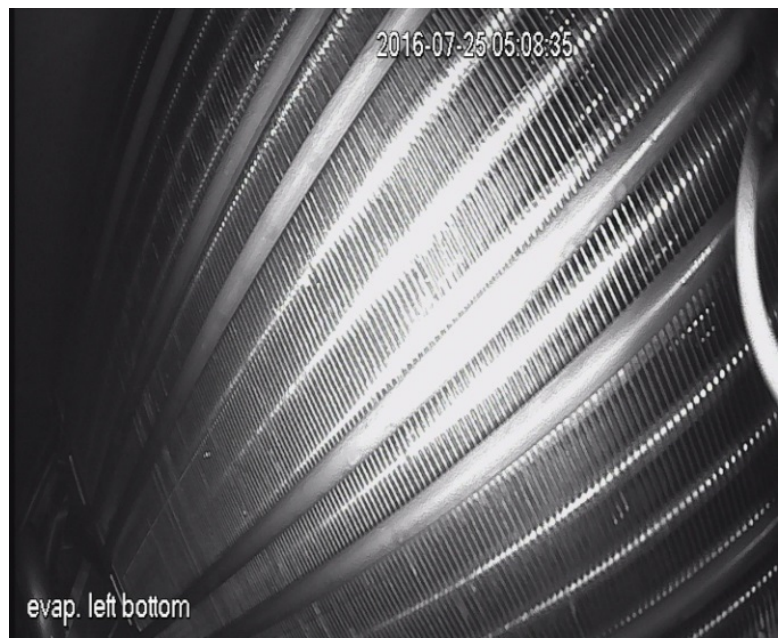

Fig. 18, cam 2 at end of defrost 7 (25-7-'16 5:00).

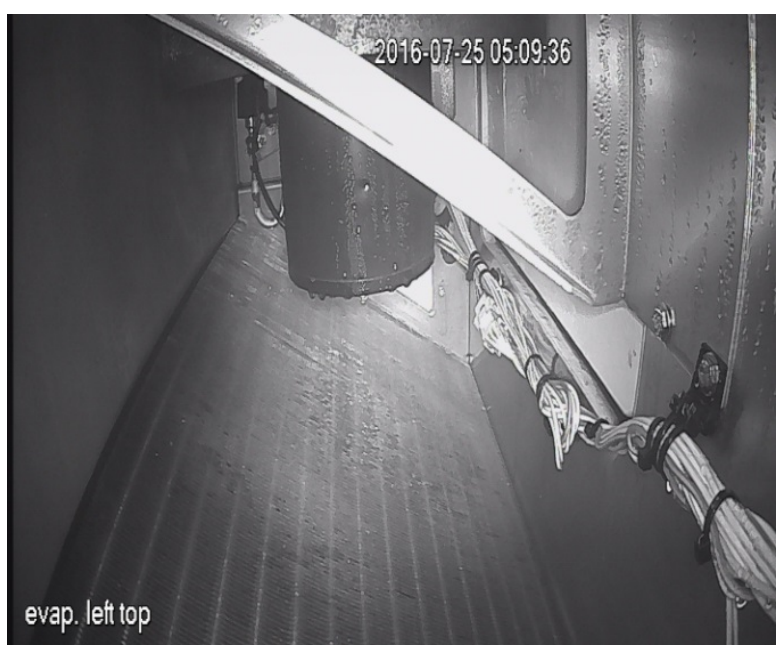

Fig. 20, cam 3 at end of defrost 7 (25-7-'16 5:00).

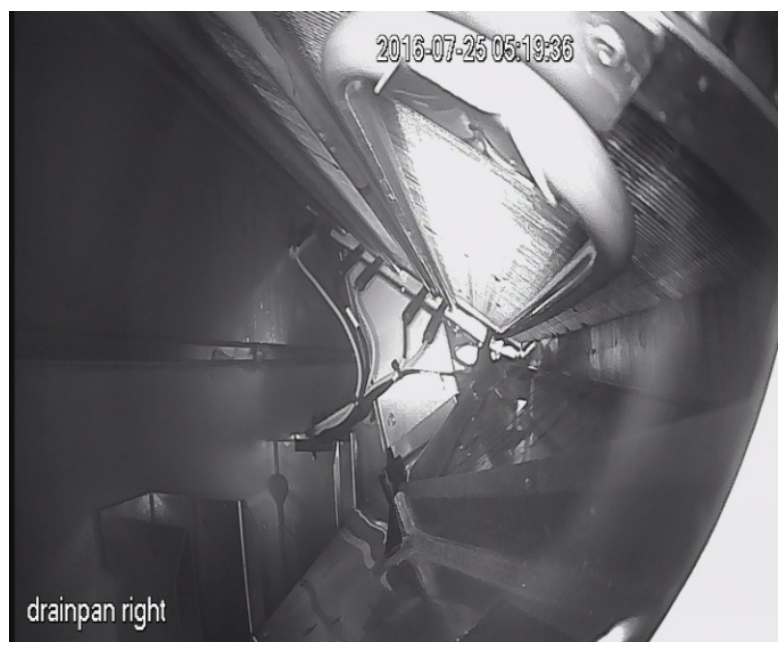

Fig. 22, cam 4 at end of defrost 7 (25-7-'16 5:00). 
Test 1 was terminated in the midst of a defrost. The return air grid was clean then (Fig. 23).

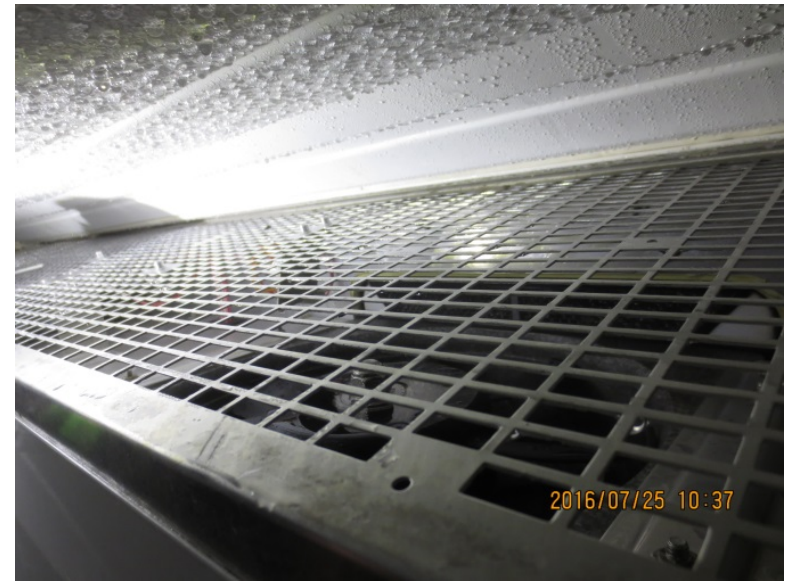

Fig. 23, return air grid at end of test 1, during

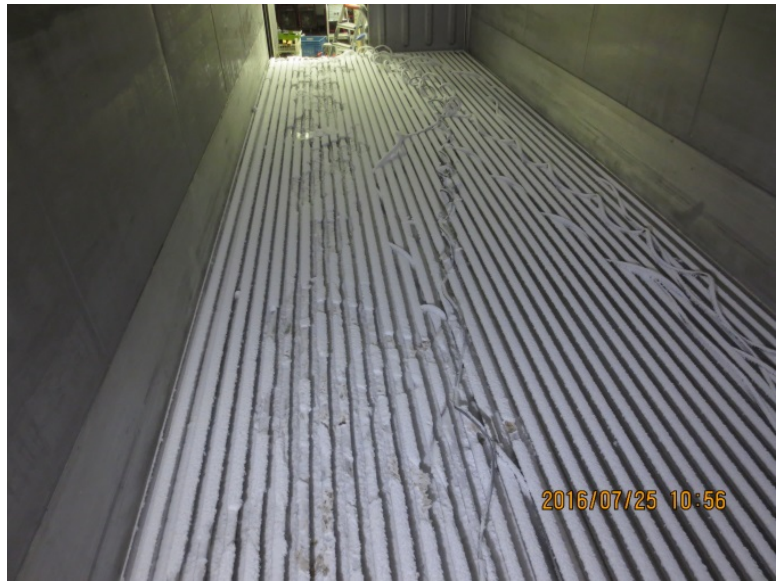

Fig. 24, snow covered floor at end of test 1 .

defrost.

At the end of test 1 hardly any ice had accumulated on the container floor underneath the unit (Fig. 26).

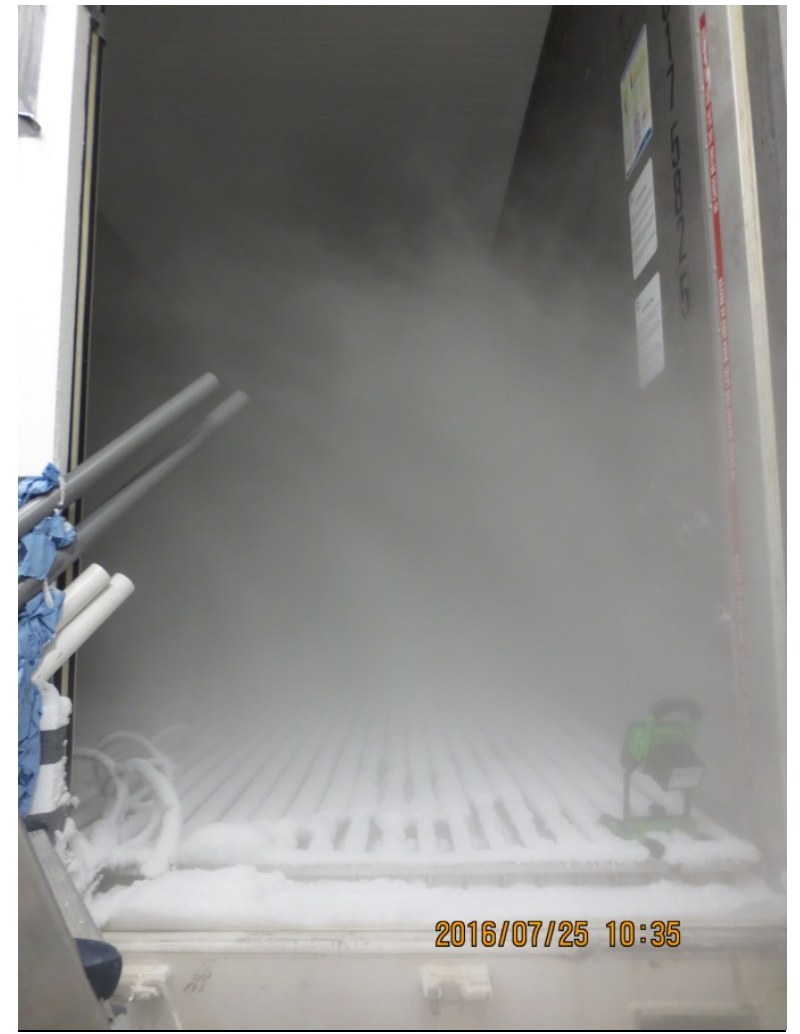

Fig. 25, snow covered floor at end of test 1.

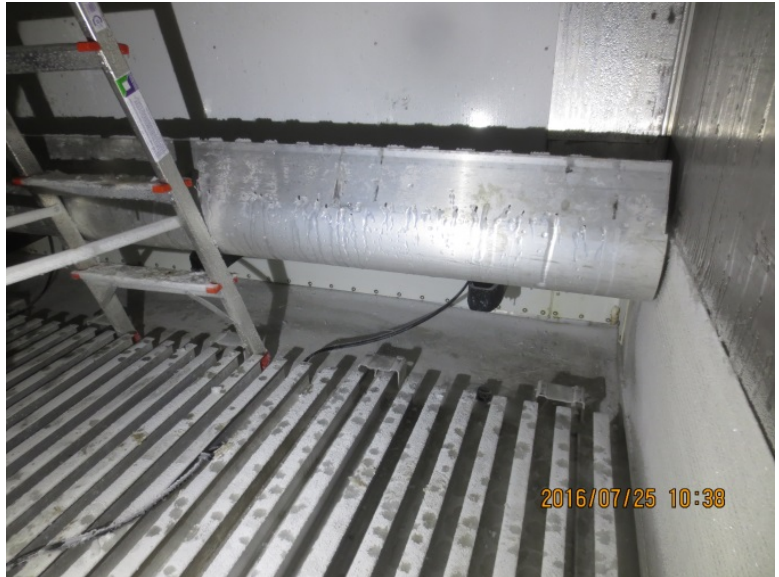

Fig. 26, very limited amount of ice accumulated underneath baffle plate at end of test 1 . 
Just before the last defrost during test 2 the container floor is free of snow (Fig. 27), while the return air grid is frosted (Fig. 28). Right after that defrost the test is terminated. At that moment the drain pans, gutters, and unit components underneath the gutters were perfectly clean (Fig. 29, Fig. 30). Fig. 27).
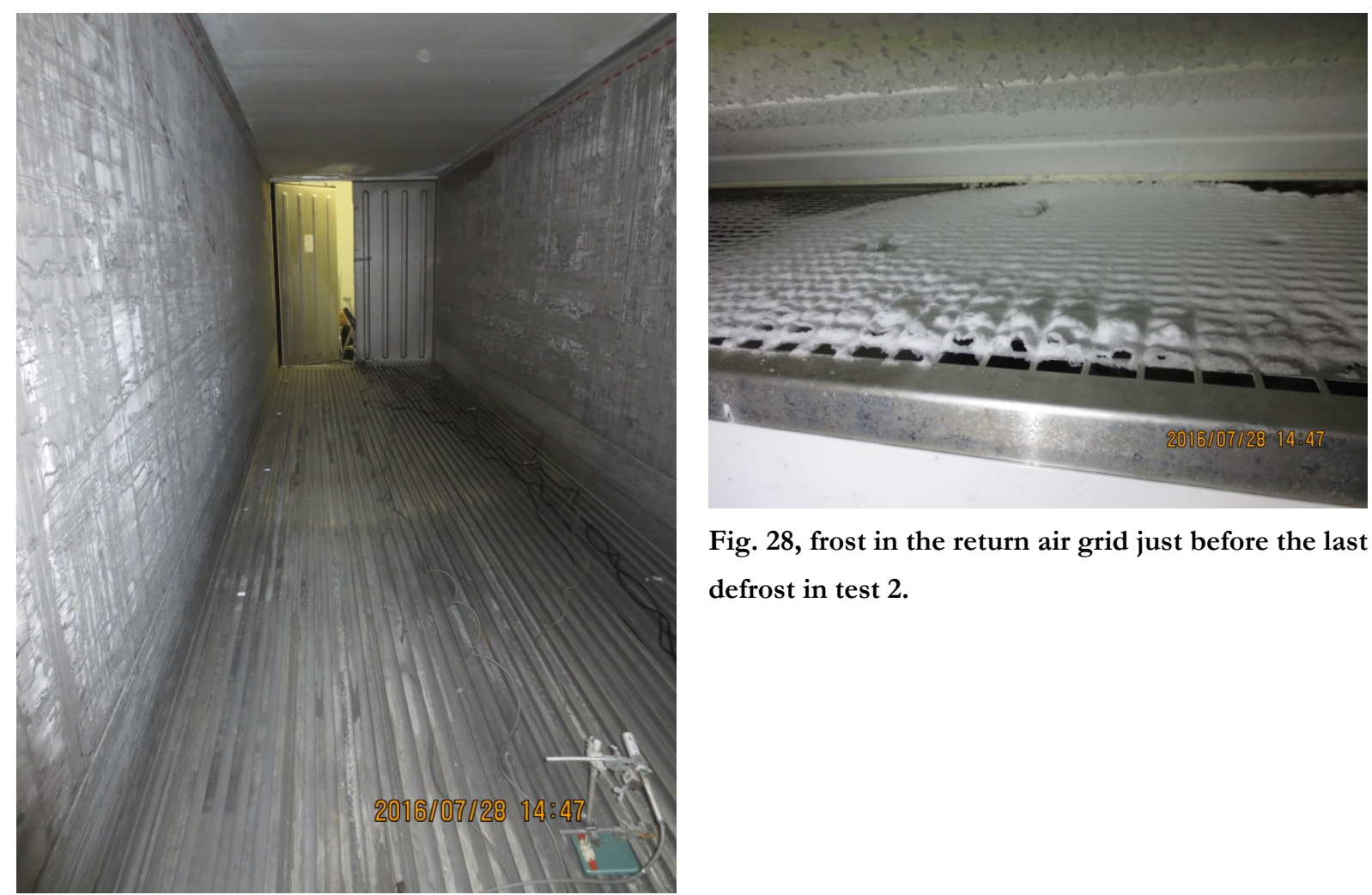

Fig. 28, frost in the return air grid just before the last defrost in test 2 .

Fig. 27, just before the last defrost in test 2 the floor is free of snow.
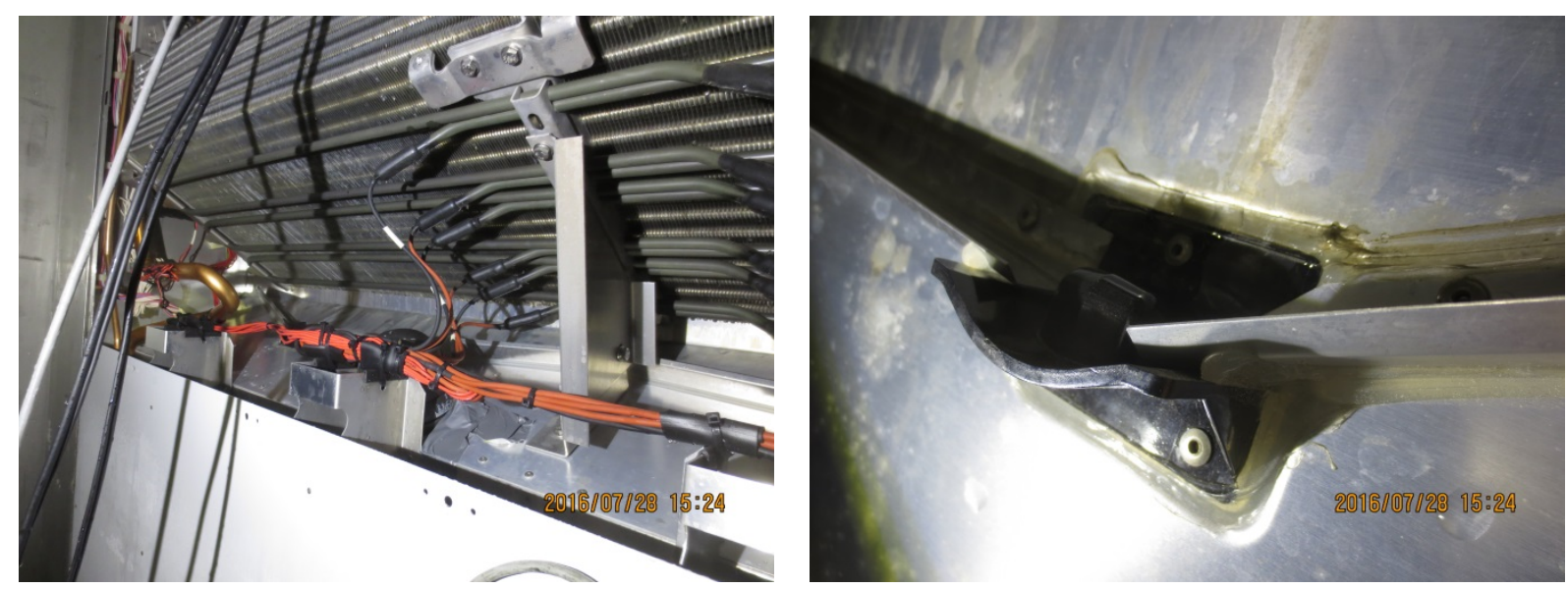

Fig. 29, at end of test 2 the floor is free of snow.

Fig. 30, clean drain pan at end of test 2 . 
Test 2 was a milder test than test 1 . Also in test 2 no ice/frost accumulation in the air flow path occurred. The only difference worth noticing is the change in defrost pattern: the average defrost interval increased only a little (compare Fig. 12 and Fig. 14). 


\section{Discussion}

In both test conditions the extended defrost function suffices to completely defrost the unit. This is proven by the persistently repetitive temperature cycle during multiple days of testing (Fig. 12, Fig. 14). Extra evidence is provided by the images not revealing any frost at the end of one of the last defrosts (Fig. 16, Fig. 18, Fig. 20, Fig. 22).

Ice accumulation underneath the unit's rear panel is negligible (Fig. 26). Apparently all melt water reaching the drain gutters also reaches the drain pans and is expelled through the drain line.

During the tests the recorded rear panel temperature ('Log'Tag' in Fig. 13) stays well below return air temperature RTS, and in-between defrosts even mostly below supply air temperature STS. In a stuffed reefer the rear panel temperature will be different due to thermal mass of product against the bulkhead, and much less air flow along the bulkhead. Yet the collected rear panel temperatures are no reason for concern.

Too many alarms occur during the test. It's mostly alarm 72. According to anonymous (2016) alarm 72 is the 'control temp out of range'-alarm, which is activated 'after the unit goes in-range for 30 minutes then out of range for a continuous 120 minutes'. It is anticipated that ETDF may well trigger this alarm in real transport as well.

The software logic (see section 2.1) has not been tested in full detail. Some defrost termination events have been analysed in detail in the datamonitor file. All defrosts terminate according to the 3 -step procedure specified in section 2.1. It has not been tested if defrosts are extended defrosts only if $\operatorname{cd} 27=$ AUTO.

The logic (see section 2.1) has an inherent weakness: it offers a good chance that the return air grid is frost-free at the end of a defrost, but does not guarantee so. This is because the decision to terminate defrosts is based on DTS, while DTS hardly correlates to the amount of frost accumulated on the return air grid. Moreover the grid status after idling for 10 minutes is completely unsure. According to Murphy's law this approach has to fail in some conditions. On the other hand, this software logic apparently suffices in the harsh test conditions covered in this report.

The tests have been performed on a 2015-design unit, while the original plan was to use a 2013or-older design. After arrival of the unit at our premises this was noticed prior to the start of testing. In view of time pressure, and because it is believed that the difference between the two designs is not an essential difference, it was decided to proceed testing on the newer design, and Maersk Line was informed about this decision. 


\section{Conclusion}

The test results indicate that Carrier's software scrl9521.ml3 is an effective solution to the ice/frost formation problem in frozen mode shipments with a high moisture load. Two concerns remain:

1. It is inherent to the implemented software logic that there is no guarantee of a frost-free return air grid at defrost termination.

2. The alarms generated during the tests deserve attention.

\section{References}

Anonymous (2016). T-362 Rev B Change 07/16. Operations and service manual for 69NT40561-200 to 299 Container Refrigeration Units.

\section{Acknowledgements}

We are grateful to Maersk Line, represented by Morten Baerentz, for the smooth cooperation. 